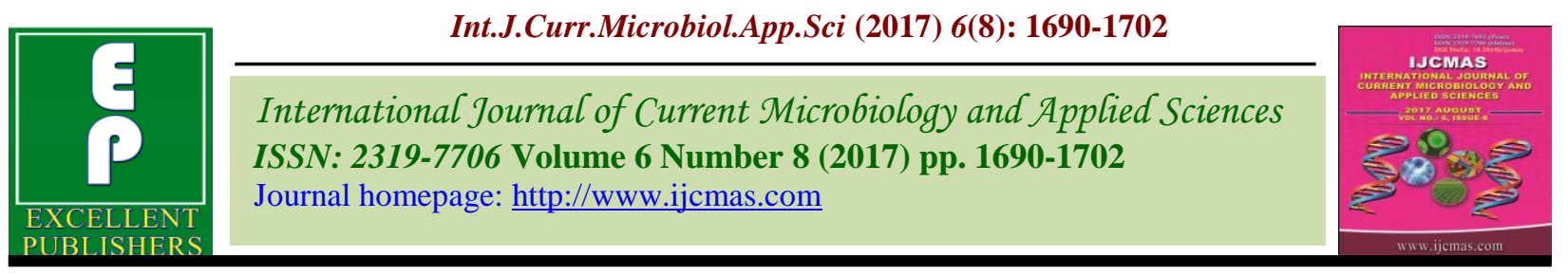

Original Research Article

https://doi.org/10.20546/ijcmas.2017.608.203

\title{
Thidiazuron Induced Direct Shoot Organogenesis in Stevia rebaudiana and Assessment of Clonal Fidelity of Regenerated Plants by RAPD and ISSR
}

\author{
Manvendra Singh*, Vinod Saharan, Deepak Rajpurohit, Yadunandan Sen, \\ Arunabh Joshi and Ajay Sharma
}

\author{
Department of Molecular Biology and Biotechnology, RCA, Maharana Pratap University of \\ Agriculture and Technology Udaipur-313001, Rajasthan, India \\ *Corresponding author
}

A B S T R A C T

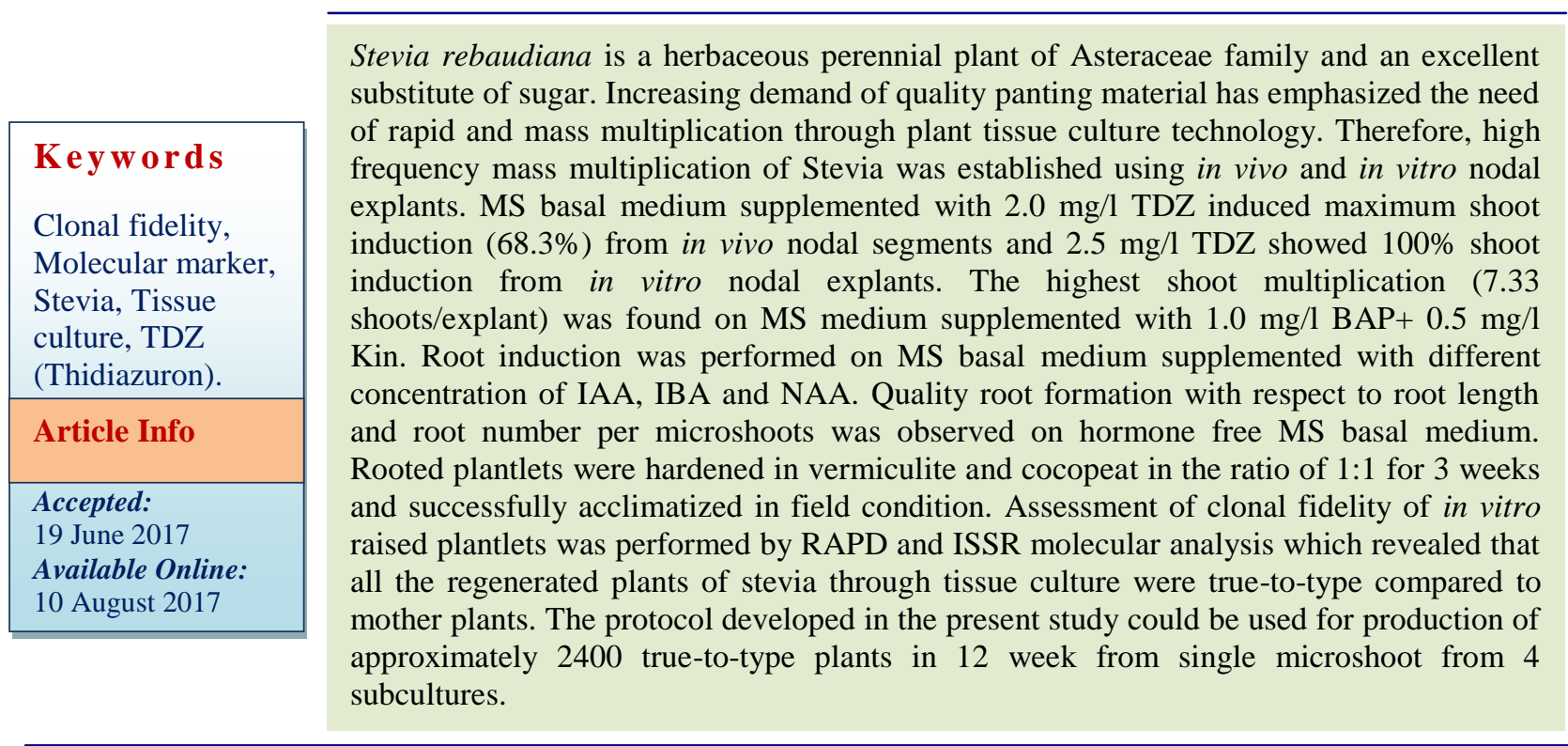

\section{Introduction}

Stevia rebaudiana Bertoni is a perennial herb of Astereace family which is native to the valley of Rio Monday in highlands of northeastern Paraguay in South America. Leaves of Stevia produce diterpene glycosides (stevioside and rebaudiosides) which serve as high-potency sweeteners and substitute to sugar (Yadav et al., 2011). The potential uses of Stevia which produces stevioside, a noncaloric sweetener that does not metabolize in the human body, hence control blood sugar level (Gantait et al., 2015). This is more important, especially in the context of the current social movement towards more natural foods.

In nature, seed germination in Stevia is poor and unsuccessful due to infertile seed and small endosperm (Shock, 1982; Carneiro et al., 1997; Goettemoeller and Ching, 1999). Even some plant selections produce virtually no viable seed due to their self- 
incompatibility (Yadav et al., 2011). Numbers of reports are available on successful propagation of Stevia via stem cuttings. But direct planting of stem cuttings in the field has limited success due to poor rooting (Yadav et al., 2011). Moreover, a huge number of stem cuttings are required for mass propagation of plants which is an obstacle as number of mother plant need to be vanishing. Hence, conventional methods are not adequate for commercial exploitation of Stevia plants and fulfill the current demand.

Micropropagation protocols of Stevia have been established using leaf (Sivaram and Mukundan, 2003; Sreedhar et al., 2008; Jain et al., 2009), nodal (Sung, 2006; Ahmed et al., 2007; Laribi et al., 2012; Modi et al., 2012; Thiyagarajan and Venkatachalam, 2012; Hassanen and Khalil, 2013; Lata et al., 2013; Singh and Dwivedi, 2013; Singh et al., 2014) and shoot tips explants (Tamura et al., 1984; Ibrahim et al., 2008a; Ibrahim et al., 2008b; Hassanen and Khalil, 2013), however, a major problem associated with in vitro culture is the possible occurrence of somaclonal variation through indirect organogenesis (Modi et al., 2012; Singh et al., 2014). Literatures revealed the occurrence of variability in tissue culture raised plants which did not produced true-to-type plants. Moreover, urgent need to the study about the effect of TDZ on in vivo and in vitro nodal explants of stevia for direct organogenesis and assessment of genetic fidelity of regenerated plants by molecular markers for commercial exploitation require prime consideration.

Therefore, the present investigation was emphasized on development of an efficient in vitro micropropagation protocol for high frequency mass multiplication of true-to-type plants and to detect the genetic uniformity of micropropagated plants of Stevia using molecular markers.

\section{Materials and Methods}

\section{Source and preparation of explants}

Nodal explants $(2.0 \mathrm{~cm})$ were collected from 6 month old plants growing at $\mathrm{Hi}$ Tech Horticulture Farm, Rajasthan College of Agriculture, Maharana Pratap University of Agriculture and technology, Udaipur. Explants were rinsed with sterile distilled water mix with few drops of Tween 20 for 10 min and rinsed thoroughly three times with sterile distilled water. Explants were disinfected by treating with $0.4 \%$ bavastin for 15 minutes with constant swirling at $110 \mathrm{rpm}$ on shaker. The solution was drained out and explants were washed properly 3-4 times with sterile distilled water. After that, explants were disinfected with freshly prepared $0.1 \%$ Mercuric chloride solution for 6 minutes with constant swirling at $110 \mathrm{rpm}$ and then rinsed 3-4 times with sterile distilled water. Tissue culture regenerated plants were also used for obtaining in vitro nodal explants.

\section{Nutrient medium and laboratory condition}

Nodal explants were cultured on MS basal (Murasnige and Skoog, 1962) medium fortified with different concentration of TDZ for shoot induction and BAP + Kin for shoot multiplication. Shoots were transferred on MS basal medium nourished with various concentrations of IBA, IAA and NAA for root induction. All media were supplemented with $3 \%(\mathrm{w} / \mathrm{v})$ sucrose and $0.8 \%(\mathrm{w} / \mathrm{v})$ agar (Himedia, Mumbai). The $\mathrm{pH}$ of MS medium was adjusted to 5.80 prior to sterilization at $121^{\circ} \mathrm{C}$ for 15 minutes at $15 \mathrm{psi}$. The culture was incubated at $25 \pm 1^{\circ} \mathrm{C}$ with $16 \mathrm{~h}$ light $/ 8 \mathrm{~h}$ dark photoperiod under the cool white fluorescent tubes (Crompton Greaves Limited, Mumbai). Subculture was done every three weeks interval with respective media. Rooted plantlets were placed in plastic pots, containing vermiculite and cocopeat (1:1) kept in plastic box to maintain high humidity. 


\section{Analysis of clonal fidelity}

Total genomic DNA was extracted from fresh young leaves of randomly selected in vitro raised plants following the CTAB method with minor modification (Doyle and Doyle, 1987). The quality of extracted DNA after RNase treatment was evaluate on $0.8 \%$ agarose gel and finally the DNA was quantified using spectrophotometer. Each DNA samples was diluted to $50 \mathrm{ng} \mathrm{ul}^{-1}$ with TE (Tris-EDTA) buffer before use and stored at $4^{\circ} \mathrm{C}$. Genetic fidelity was performed on in vitro regenerated Stevia plants by direct organogenesis. DNA samples were subjected to polymerase chain reaction (PCR) to generate fingerprinting pattern using RAPD and ISSR primers obtained from OPERON Technologies, USA. Selected 35 RAPD and twenty five ISSR primers were tested for genetic uniformity assay depending reproducible banding pattern (Tables 1 and 2). RAPD-PCR (Modi et al., 2012) and ISSRPCR (Singh et al., 2014) was performed as per standardized protocol for Stevia. PCR reactions were repeated to confirm the reproducibility of the banding pattern.

\section{Statistical analysis}

For in vitro tissue culture experiments, statistical analysis were performed with JMP software version 9 using Tukey Kramer HSD test to determines significant differences among treatment at $\mathrm{P} \leq 0.05$.

\section{Results and Discussion}

\section{Shoot induction from in vivo and in vitro nodal explants}

Mass multiplication protocol was established from in vivo nodal explants. Sterilized nodal explants $(1.0-2.0 \mathrm{~cm})$ were cultured on various concentration of TDZ (0.5-3.0 mg/l). Almost at every concentration of TDZ, bud break was observed during 3-8 days after inoculation (Fig. 1 A). After two weeks on various shoot induction medium, maximum 23 microshoots emerged from nodes. The highest shoot induction (68.3\%) was observed at $2.0 \mathrm{mg} / \mathrm{l} \mathrm{TDZ}$. At higher concentration of TDZ (2.5-3.0 mg/l), shoot induction percentage significantly decreased (Table 3).

In vitro nodal explants $(2-3 \mathrm{~cm})$ derived from in vitro regenerated plants were cultured on various concentration of TDZ $(0.5-3.0 \mathrm{mg} / \mathrm{l})$. In all concentration of TDZ, shoot induction was noted during 3-5 days after inoculation. After two weeks on various shoot induction medium, maximum 2-5 microshoots was observed from in vitro nodal segments (Fig. 1 B). The lowest shoot induction percentage was $61.66 \%$ at $0.5 \mathrm{mg} / \mathrm{l} \mathrm{TDZ}$ while $2.5 \mathrm{mg} / \mathrm{l}$ TDZ showed $100 \%$ shoot induction. At higher concentration of TDZ $(3.0 \mathrm{mg} / \mathrm{l})$, Shoot induction percentage significantly decreased (Table 4).

\section{Shoot multiplication}

MS basal media were used for shoot multiplication with various concentration of BAP $(1.0-2.0 \mathrm{mg} / \mathrm{l})$ in combination with 0.5 mg/l Kin (Fig. 1 C, D). After 3 weeks of culture on different shoot multiplication medium, maximum shoots per explants (7.3) were observed at $1.0 \mathrm{mg} / \mathrm{l}$ BAP in combination with $0.5 \mathrm{mg} / \mathrm{l} \mathrm{Kin}$ (Table 6).

\section{Rooting and acclimatization}

For root induction, shoots $(\geq 2 \mathrm{~cm})$ were placed on MS basal medium nourished with different concentration of IAA $(0.2-1.0 \mathrm{mg} / \mathrm{l})$, IBA $(0.2-1.0 \mathrm{mg} / \mathrm{l})$ and NAA $(0.2-1.0 \mathrm{mg} / \mathrm{l})$. First root was emerged after 8 days of culture on IAA $(1.0 \mathrm{mg} / \mathrm{l})$, NAA $(1.0 \mathrm{mg} / \mathrm{l})$ and hormone free MS basal medium. Highest rooting response $(91.66 \%)$ was noticed on 
hormone free media with quality roots (Fig. 1 $\mathrm{E})$, in respect to root numbers and root length (Table 5). However, certain concentration of IAA, IBA and NAA, roots emerged from callus at the base of shoots and these roots are detached from shoots during subculture. The rooted plantlets were successfully transferred in plastic pots containing cocopeat and vermiculite in the ratio $1: 1$. The pots were placed in a plastic box and covered with lid to ensure high humidity (Fig. 1 F). Boxes were kept in controlled condition for 3 weeks and then transferred to poly house (Fig. 1 G). All plantlets were transferred in field condition with $98.66 \%$ survival (Table 7 ).

\section{Analysis of clonal fidelity}

RAPD and ISSR molecular markers were used to estimate the genetic stability at the DNA level of regenerated Stevia plants from nodal explants (Tables 1 and 2). Thirty five RAPD primers and 25 ISSR primers were screened out of which 22 primers of RAPD and 10 primers of ISSR amplified and displayed monomorphic banding pattern in all the 19 randomly selected micropropagated plants and the mother plant (Fig. 2, 3).

\section{Shoot induction}

In present investigation, compared the effect of different concentration of TDZ for shoot induction from nodal explant of Stevia, surface sterilized nodal explants were cultured on different concentration of (TDZ 0.5-3.0 $\mathrm{mg} / \mathrm{l})$. Almost at every concentration of TDZ, bud break was noted during 3-6 days after inoculation. Highest shoot induction $(68.3 \%)$ was observed at $2.0 \mathrm{mg} / \mathrm{l}$ TDZ. It was observed that at lower and higher concentration of TDZ, shoots induction percentage was less. In the present study, no significant differences were observed at lower (1.0-1.5 mg/l) and higher (2.5-3.0 mg/l) concentration of TDZ. TDZ appears to mimic cytokinin-like activity causing the release of lateral buds and showed better response in terms of shoot regeneration efficiency, compared to other cytokinins, similar to other findings where TDZ produced shoots comparable to or greater than that of other cytokinins (Murthy and Murch, 1998; Ramírez-Mosqueda and Iglesias-Andreu, 2016; Rout et al., 2000; Singh and Dwivedi, 2013).

\section{Shoot multiplication}

For shoot multiplication, induced shoots were cultured on MS basal media supplemented with different concentration of BAP (0.5-1.0 $\mathrm{mg} / \mathrm{l})$ in combination with Kin $(0.5 \mathrm{mg} / \mathrm{l})$. BAP in combination with Kin was efficient cytokinin for multiple shoot bud regeneration. Maximum shoot multiplication shoots per explants (7.3) were recorded at $1.0 \mathrm{mg} / \mathrm{l} \mathrm{BAP}$ in combination of $0.5 \mathrm{mg} / \mathrm{l} \mathrm{Kin}$. Increasing the BAP concentration higher than $1.0 \mathrm{mg} / \mathrm{l}$, plant regeneration frequency and the number of shoots per culture significantly decreased (Ibrahim et al., 2008a). In previous published reports, similar trends were observed (Sivaram and Mukundan, 2003; Ahmed et al., 2007; Ibrahim et al., 2008a; Jain et al., 2009; Atalay et al., 2011; Laribi et al., 2012; Modi et al., 2012; Gantait et al., 2015).

\section{Rooting}

Shoots were placed on MS basal medium fortified with various concentrations of IAA, IBA and NAA for root induction (Rout et al., 2000). After a week of culture roots emerged, beside hormone free media, shoots showed different level of callusing and false roots were noticed (Ibrahim et al., 2008a; Ibrahim et al., 2008b; Gantait et al., 2015). Shoots having roots emerged from callus was detached during subculture. Highest rooting response was observed on hormone free media with quality roots in respect to root 
numbers and root length (Table 3). Previous literature revealed the occurrence of rooting response in media supplemented with IAA, NAA and IBA (Sivaram and Mukundan, 2003; Atalay et al., 2011; Modi et al., 2012; Thiyagarajan and Venkatachalam, 2012; Singh and Dwivedi, 2013; Singh et al., 2014). However, in present study, the quality root formation was reported on the basis of root number, root length with superior rooting response on hormone free medium.

\section{Acclimatization}

Acclimatization of regenerated plantlets is the most important phase for a reproducible micropropagation protocol of Stevia. Hardening media is influenced by light, temperature and humidity during acclimatization (Pospisilova et al., 1999; Hazarika, 2006; Vasane and Kothari, 2008; Awang et al., 2009; Talukdar and Bora, 2009). Therefore, various combinations of substrates were used in hardening phase (Table 4). Highest survivals of regenerated plantlets were observed in cocopeat and vermiculite in ratio of $1: 1$. In this investigation, hardening procedure is well established and survival rate was found higher than in previous published reports (Sivaram and Mukundan, 2003; Sung, 2006; Jain et al., 2009; Atalay et al., 2011; Modi et al., 2012; Thiyagarajan and Venkatachalam, 2012; Singh and Dwivedi, 2013; Gantait et al., 2015; Ramírez-Mosqueda and IglesiasAndreu, 2016).

\section{Clonal fidelity}

Somaclonal variations arose due toin vitro stresses and are noticeable in the form of DNA methylation, chromosome rearrangements and point mutations (Lee and Phillips, 1988; Phillips et al., 1994). Consequently, an assessment to ensure trueto-type propagules at an early stage of development is considered to be very useful in micropropagation system (Mohan Jain, 2001). To assess the clonal fidelity of micropropagated plantlets several approaches were taken such as molecular approaches. Detection of genetic variation is essential for micropropagation as well as in vitro germplasm conservation to eradicate detrimental somaclonal variations (Kaeppler et al., 2000; Mohan Jain, 2001). PCR-based techniques have been found to be greatly useful in establishing the genetic stability of cultivated as well as in vitro regenerated Stevia plants (Modi et al., 2012; Singh et al., 2014). RAPD and ISSR markers used for fidelity test and results indicated that all the tissue cultured derived plants are true-to-type and there are no somaclonal variations among those plants (Modi et al., 2012; Singh et al., 2014). The current report of Singh et al., (2014) showed that genetic fidelity of micropropagated stevia plantlets was assessed by ISSR analysis confirming that in vitro plants obtained from callus showed genetic variation during the period of culturing, whereas those from nodal segments did not. In this study, we observed that RAPD and ISSR markers ensure the genetic stability without any callusing phase.

Earlier, it was reported that Stevia plants micropropagated from callus culture, showed high level of genetic variation (Singh et al., 2014). Besides this, stevia crop is cross pollinated and high level of heterogenesity exists in the germplasm. Therefore, it is imperative that micropropagated Stevia plant must be screened for genetic variation along with their mother plant. In our study, the mother plants were selected on the basis of morphology and stevioside content (data not shown). Hence, micropropagated Stevia plants maintain similar characteristics with genetic uniformity. 
Table.1 RAPD primers used in genetic fidelity analysis of tissue culture raised plants of $S$. rebaudiana

\begin{tabular}{|c|c|c|}
\hline S. No. & Name of Primer & $\begin{array}{l}\text { Primer sequence/ } \\
\text { nucleotide sequence (5'- } \\
\text { 3') }\end{array}$ \\
\hline 1 & OPM-01 & GTTGGTGGCT \\
\hline 2 & OPM-02* & ACAACGCCTC \\
\hline 3 & OPM-03 & GGGGGATGAG \\
\hline 4 & OPM-04 & GGCGGTTGTC \\
\hline 5 & OPM-05 & GGGAACGTGT \\
\hline 6 & OPM-06 & CTGGGCAACT \\
\hline 7 & OPM-07 & CCGTGACTCA \\
\hline 8 & OPM-08 & TCTGTTCCCC \\
\hline 9 & OPM-09 & GTCTTGCGGA \\
\hline 10 & OPM-10 & TCTGGCGCAC \\
\hline 11 & OPM-12 & GGGACGTTGG \\
\hline 12 & OPZ-01 & TCTGTGCCAC \\
\hline 13 & OPZ-02* & CCTACGGGGA \\
\hline 14 & OPZ-03 & CAGCACCGCA \\
\hline 15 & OPZ-04 & AGGCTGTGCT \\
\hline 16 & OPZ-05 & TCCCATGCTG \\
\hline 17 & OPZ-06 & GTGCCGTTCA \\
\hline 18 & OPZ-07 & CCAGGAGGAC \\
\hline 19 & OPZ-08 & GGGTGGGTAA \\
\hline 20 & OPZ-09 & CACCCCAGTC \\
\hline 21 & OPZ-10 & CCGACAAACC \\
\hline 22 & OPE-4 & GTGACATGCC \\
\hline 23 & OPH-3 & AGTCGTCCCC \\
\hline 24 & OPH-13 & GACGCCACAC \\
\hline 25 & OPG-07* & GAACCTGCGG \\
\hline 26 & OPP-01* & GTAGCACTCC \\
\hline 27 & OPP-02* & TCGGCACGCA \\
\hline 28 & OPP-04* & GTGTCTCAGG \\
\hline 29 & OPP-05* & CCCCGGTAAC \\
\hline 30 & OPP-06* & GTGGGCTGAC \\
\hline 31 & OPP-07* & GTCCATGCCA \\
\hline 32 & OPP-08* & ACATCGCCCA \\
\hline 33 & OPP-09* & GTGGTCCGCA \\
\hline 34 & OPP-03* & CTGATACGCC \\
\hline 35 & OPP-10* & TCCCGCCTAC \\
\hline
\end{tabular}

* Did not amplify 
Table.2 ISSR primers used in genetic fidelity analysis of tissue culture raised plants of $S$. rebaudiana

\begin{tabular}{|c|c|c|}
\hline S. No & Name of Primer & $\begin{array}{l}\text { Primer sequence/ nucleotide sequence } \\
\left(5^{\prime}-3^{\prime}\right)\end{array}$ \\
\hline 1 & UBC-808 & AGAGAGAGAGAGAGAGC \\
\hline 2 & UBC-809 & AGAGAGAGAGAGAGAGG \\
\hline 3 & UBC-810* & GAGAGAGAGAGAGAGAT \\
\hline 4 & UBC-811 & GAGAGAGAGAGAGAGAC \\
\hline 5 & UBC $812^{*}$ & GAGAGAGAGAGAGAGAA \\
\hline 6 & UBC-813* & СТСТСТСТСТСТСТСТT \\
\hline 7 & UBC-814* & СТСТСТСТСТСТСТСТА \\
\hline 8 & UBC-815* & СТСТСТСТСТСТСТСТG \\
\hline 9 & UBC-817* & CACACACACACACACAA \\
\hline 10 & UBC-818* & CACACACACACACACAG \\
\hline 11 & UBC-823 & TCTCTCTCTCTCTCTCC \\
\hline 12 & UBC-835 & AGAGAGAGAGAGAGAGYC \\
\hline 13 & UBC-836 & AGAGAGAGAGAGAGACYA \\
\hline 14 & UBC-891 & HVHTGTGTGTGTGTGTG \\
\hline 15 & UBC-895 & AGAGTTGGTAGCTCTTGATC \\
\hline 16 & HB08 & GAGAGAGAGAGAGG \\
\hline 17 & HB12* & CACCACCACGC \\
\hline 18 & HB15* & GTGGTGGTGGC \\
\hline 19 & $(\mathrm{AAG})_{6} \mathrm{Y}$ & AAGAAGAAGAAGAAGAAGY \\
\hline 20 & $(\mathrm{GGAT})_{4} \mathrm{H}^{*}$ & GGATGGATGGATGGATH \\
\hline 21 & ISSR $844 B^{*}$ & СТСТСТСТСТСТСТСТGC \\
\hline 22 & ISSR 17898A* & CACACACACACAAC \\
\hline 23 & ISSR 17898B* & CACACACACACAGT \\
\hline 24 & ISSR HB-11* & GTGTGTGTGTGTCC \\
\hline 25 & (GGGGT)3M* & GGGGTGGGGTGGGGTM \\
\hline
\end{tabular}

Table.3 Effect of different concentration of TDZ supplemented in MS basal media on shoot induction of Stevia rebaudiana data was observed after 2 nd week

\begin{tabular}{|c|c|}
\hline TDZ (mg/l) & \% Shoot induction \\
\hline 0.5 & $20.00 \pm 2.88^{\mathrm{c}}$ \\
\hline 1.0 & $25.00 \pm 2.88^{\mathrm{c}}$ \\
\hline 1.5 & $38.33 \pm 1.63^{\mathrm{b}}$ \\
\hline 2.0 & $68.33 \pm 1.66^{\mathrm{a}}$ \\
\hline 2.5 & $38.33 \pm 1.61^{\mathrm{b}}$ \\
\hline 3.0 & $23.33 \pm 1.69^{\mathrm{c}}$ \\
\hline
\end{tabular}

Values are the mean of $3(\mathrm{n}=3)$. Means and SE followed by different letters are significant different at $\mathrm{p}<0.05$ by Tukey- Kramer HSD by JMP @ 9.0.0 software 
Table.4 Effect of different concentration of TDZ supplemented MS basal media on shoot induction from in vitro nodal explants of Stevia rebaudiana. Data was observed after 2-week

\begin{tabular}{|c|c|}
\hline TDZ (mg/l) & \% Shoot induction \\
\hline 0.5 & $61.6 \pm 1.66^{\mathrm{e}}$ \\
\hline 1.0 & $71.6 \pm 1.66^{\mathrm{d}}$ \\
\hline 1.5 & $73.3 \pm 1.66^{\mathrm{d}}$ \\
\hline 2.0 & $90.3 \pm 0.66^{\mathrm{d}}$ \\
\hline 2.5 & $100 \pm 0.0^{\mathrm{a}}$ \\
\hline 3.0 & $81.6 \pm 1.66^{\mathrm{c}}$ \\
\hline
\end{tabular}

Values are the mean of $3(\mathrm{n}=3)$. Means and SE followed by different letters are significant different at $\mathrm{p}<0.05$ by Tukey- Kramer HSD by JMP @ 9.0.0 software

Table.5 Effect of different concentration of IAA, IBA and NAA supplemented in MS basal media on root induction of $S$. rebaudiana data was observed after 2 week

\begin{tabular}{|c|c|c|c|c|c|c|}
\hline \multicolumn{3}{|c|}{ Auxins (mg/l) } & \multirow{2}{*}{$\begin{array}{c}\text { No of } \\
\text { average } \\
\text { root/shoot }\end{array}$} & \multirow{2}{*}{$\begin{array}{l}\text { Mean root } \\
\text { length }\end{array}$} & \multirow{2}{*}{$\begin{array}{c}\text { Rooting } \\
\text { response }(\%)\end{array}$} & \multirow{2}{*}{ Callusing } \\
\hline IBA & IAA & NAA & & & & \\
\hline Control & & & $6.32 \pm 0.15^{b}$ & $3.72 \pm 0.20^{\mathrm{a}}$ & $91.66 \pm 1.66^{\mathrm{a}}$ & - \\
\hline 0.2 & & & $3.92 \pm 0.70^{\mathrm{bc}}$ & $0.96 \pm 0.03^{b}$ & $20.00 \pm 2.88^{\mathrm{d}}$ & - \\
\hline 0.4 & & & $4.33 \pm 0.19^{b}$ & $0.88 \pm 0.05^{\mathrm{b}}$ & $58.33 \pm 1.66^{\mathrm{b}}$ & ++ \\
\hline 0.6 & & & $6.19 \pm 0.25^{\mathrm{a}}$ & $0.32 \pm 0.01^{\mathrm{c}}$ & $58.33 \pm 4.40^{\mathrm{b}}$ & +++ \\
\hline 0.8 & & & $2.22 \pm 0.40^{\mathrm{c}}$ & $0.32 \pm 0.01^{\mathrm{c}}$ & $13.33 \pm 1.66^{\mathrm{d}}$ & +++ \\
\hline 1.0 & & & $2.72 \pm 0.14^{b c}$ & $0.34 \pm 0.00^{\mathrm{c}}$ & $10.00 \pm 2.88^{d}$ & +++ \\
\hline & 0.2 & & $5.78 \pm 0.04^{b c}$ & $3.73 \pm 0.08^{a}$ & $70.00 \pm 5.77^{b}$ & - \\
\hline & 0.4 & & $5.10 \pm 0.19^{c}$ & $2.25 \pm 0.02^{b}$ & $78.33 \pm 1.66^{b}$ & + \\
\hline & 0.6 & & $6.02 \pm 0.16^{\mathrm{b}}$ & $2.17 \pm 0.01^{b c}$ & $78.33 \pm 1.66^{\mathrm{b}}$ & + \\
\hline & 0.8 & & $13.98 \pm 0.16^{\mathrm{a}}$ & $1.73 \pm 0.06^{\mathrm{c}}$ & $98.33 \pm 1.66^{\mathrm{a}}$ & + \\
\hline & 1.0 & & $3.64 \pm 0.05^{\mathrm{d}}$ & $1.85 \pm 0.03^{b c}$ & $98.33 \pm 1.66^{\mathrm{a}}$ & + \\
\hline & & 0.2 & $7.90 \pm 0.21^{\mathrm{a}}$ & $1.84 \pm 0.01^{b}$ & $93.33 \pm 3.33^{\mathrm{a}}$ & + \\
\hline & & 0.4 & $5.57 \pm 0.35^{\mathrm{b}}$ & $0.71 \pm 0.02^{c}$ & $76.66 \pm 1.66^{b}$ & - \\
\hline & & 0.6 & $8.93 \pm 0.44^{\mathrm{a}}$ & $0.53 \pm 0.00^{c}$ & $56.66 \pm 3.33^{c}$ & ++ \\
\hline & & 0.8 & $3.41 \pm 0.12^{\mathrm{c}}$ & $0.53 \pm 0.00^{c}$ & $51.66 \pm 4.40^{c}$ & +++ \\
\hline & & 1.0 & $2.38 \pm 0.20^{c}$ & $0.32 \pm 0.01^{\mathrm{c}}$ & $18.33 \pm 1.66^{\mathrm{d}}$ & ++++ \\
\hline
\end{tabular}

Values are the mean of $3(n=3)$. Means and SE followed by different letters are significant different at $\mathrm{p}<0.05$ by Tukey- Kramer HSD by JMP @ 9.0.0 software 
Table.6 Effect of different concentration of BAP and Kin supplemented in MS basal media on shoot multiplication of Stevia rebaudiana data was observed after 3 week

\begin{tabular}{|c|c|c|}
\hline \multirow{2}{*}{ Cytokinin $(\mathbf{m g} / \mathbf{l})$} & \multicolumn{2}{|c|}{ III Week } \\
\cline { 2 - 3 } & No of shoots/explant & Mean shoot Length \\
\hline $1.0 \mathrm{BAP}+0.5 \mathrm{Kin}$ & $7.33 \pm 0.14^{\mathrm{a}}$ & $1.63 \pm 0.08^{\mathrm{a}}$ \\
\hline $1.5 \mathrm{BAP}+0.5 \mathrm{Kin}$ & $5.56 \pm 0.12^{\mathrm{b}}$ & $0.56 \pm 0.05^{\mathrm{b}}$ \\
\hline $2.0 \mathrm{BAP}+0.5 \mathrm{Kin}$ & $4.51 \pm 0.13^{\mathrm{c}}$ & $0.57 \pm 0.06^{\mathrm{b}}$ \\
\hline
\end{tabular}

Values are the mean of $3(n=3)$. Means and SE followed by different letters are significant different at $\mathrm{p}<0.05$ by Tukey- Kramer HSD by JMP @ 9.0.0 software

Table.7 Effect of different type of hardening material used for survival of regenerated plantlets of $S$. rebaudiana. Data was observed after 3-weeks

\begin{tabular}{|c|c|}
\hline Hardening material (ratio 1:1) & \% survival plants \\
\hline Cocopeat+vermiculite & $98.66 \pm 1.33^{\mathrm{a}}$ \\
\hline Cocopeat+vermicompost & $77.33 \pm 3.52^{\mathrm{b}}$ \\
\hline Cocopeat+sand & $28.00 \pm 2.30^{\mathrm{d}}$ \\
\hline Cocopeat+perlite & $52.00 \pm 4.00^{\mathrm{c}}$ \\
\hline Vermiculite+vermicompost & $44.00 \pm 4.61^{\mathrm{c}}$ \\
\hline
\end{tabular}

Values are the mean of $3(n=3)$. Means and SE followed by different letters are significant different at $\mathrm{p}<0.05$ by Tukey- Kramer HSD by JMP @ 9.0.0 software

Fig.1 (A) Shoot induction from in vivo nodal explants, (B) Shoot induction from in vitro nodal explants, (C, D) Shoot multiplication, (E) Rooting, (F, G) Hardening of regenerated plantlets

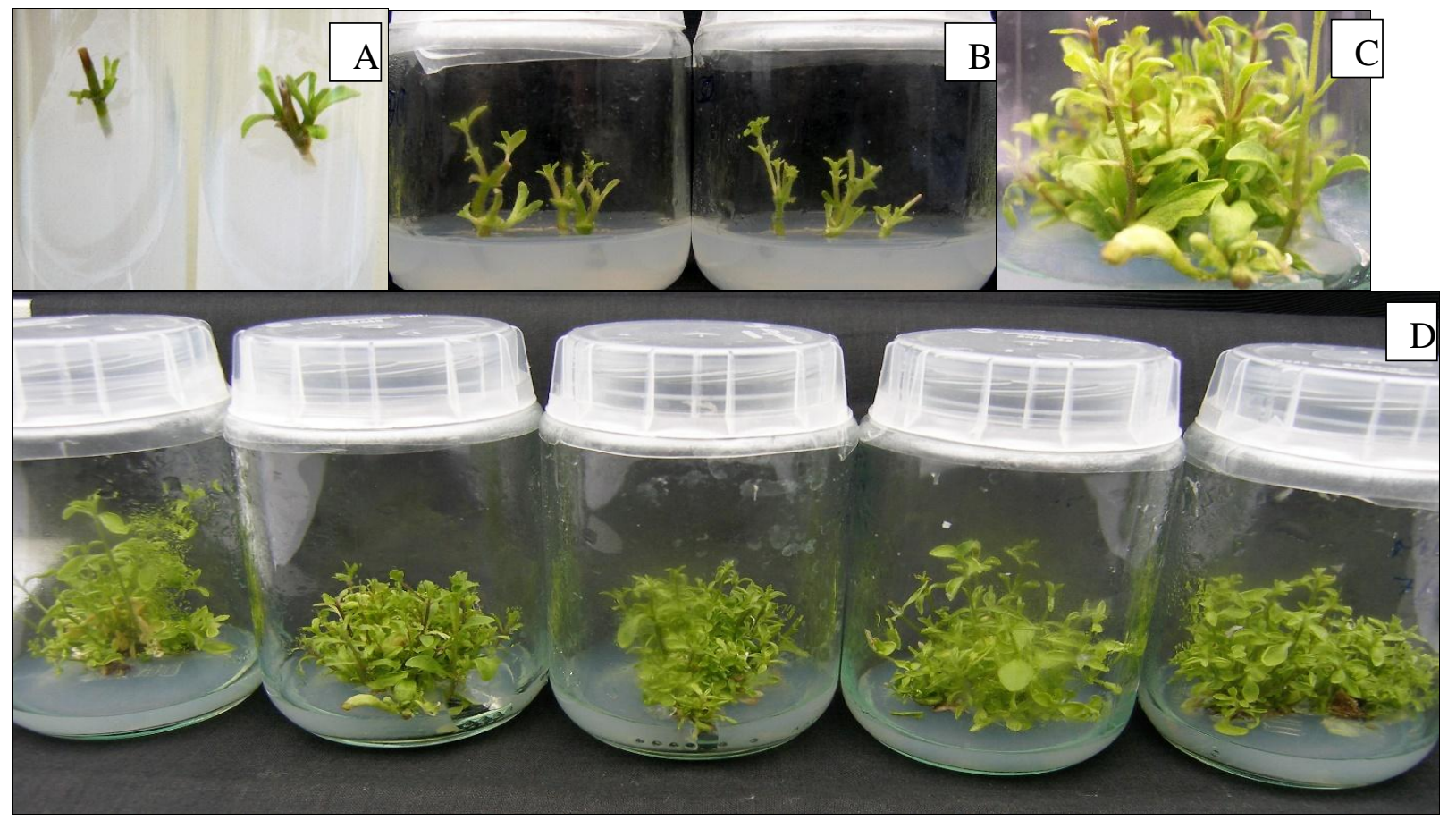




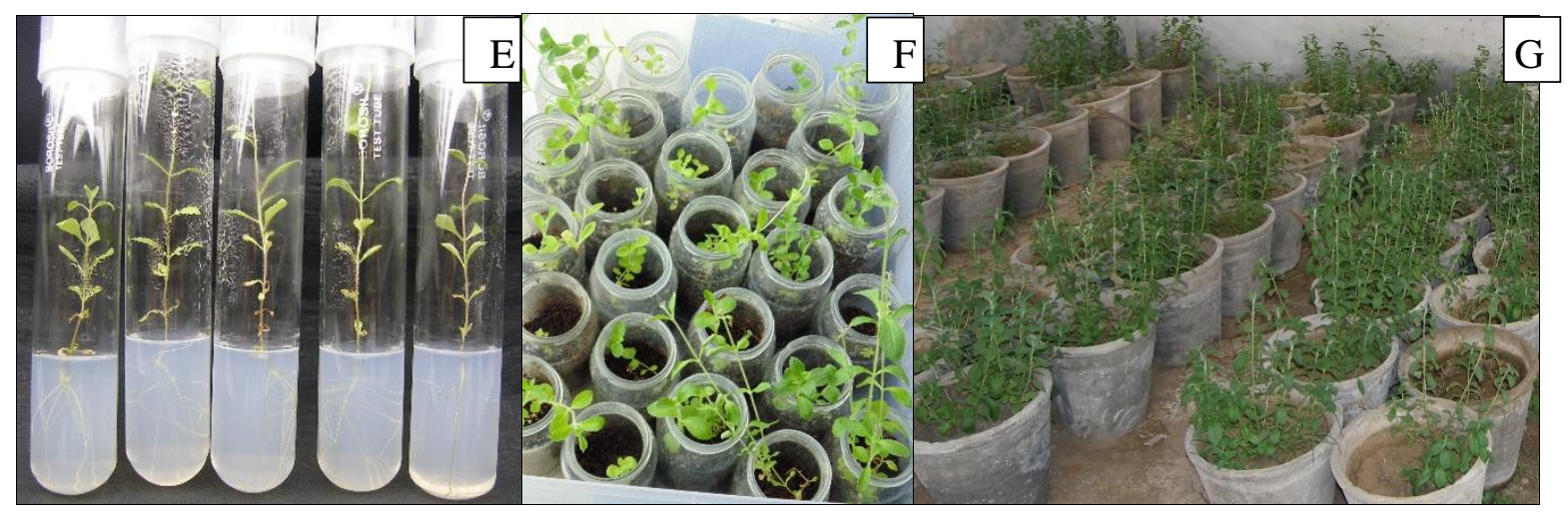

Fig.2 DNA fingerprint pattern generated with primers OPM-06. M1 and M2-DNA marker, lane S36 - DNA from mother plant, lanes R1 to R19 - DNA from tissue culture raised plants

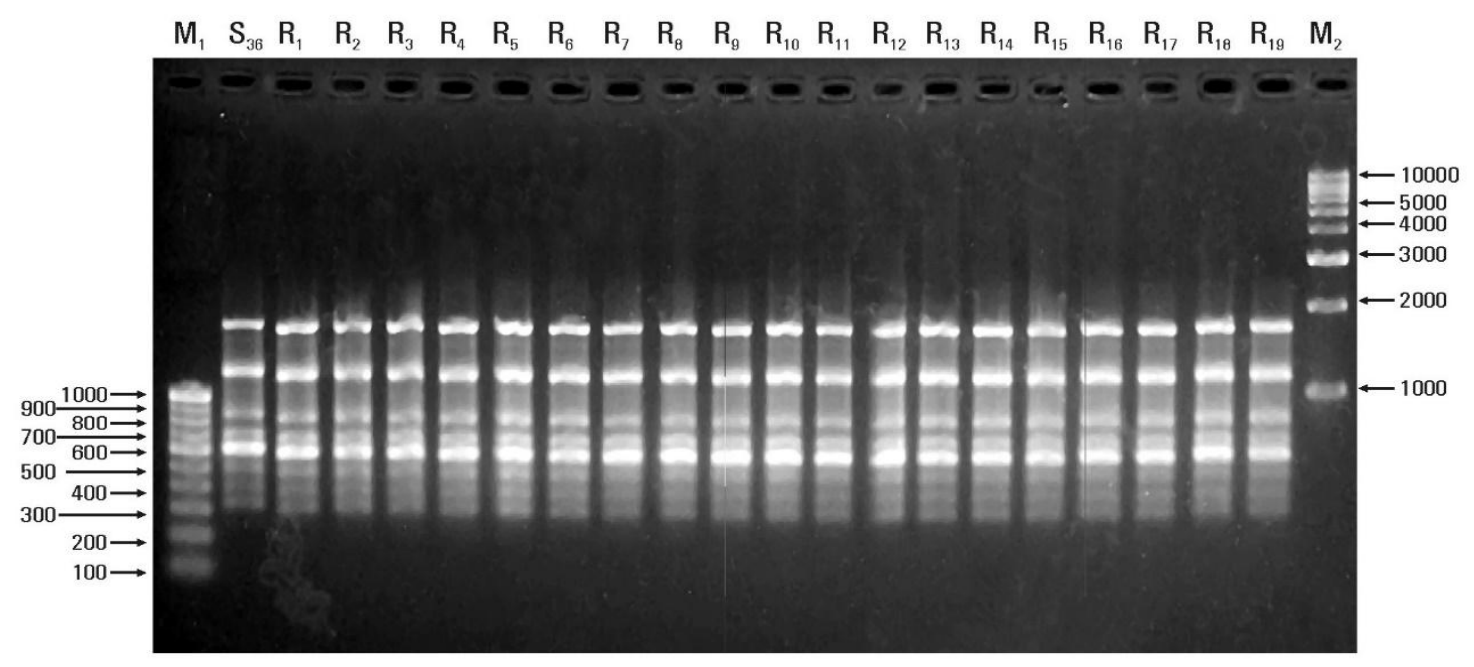

Fig.3 DNA fingerprint pattern generated with primers UBC-811. M1 and M2-DNA marker, lane S36 - DNA from mother plant, lanes R1 to R19 - DNA from tissue culture raised plants

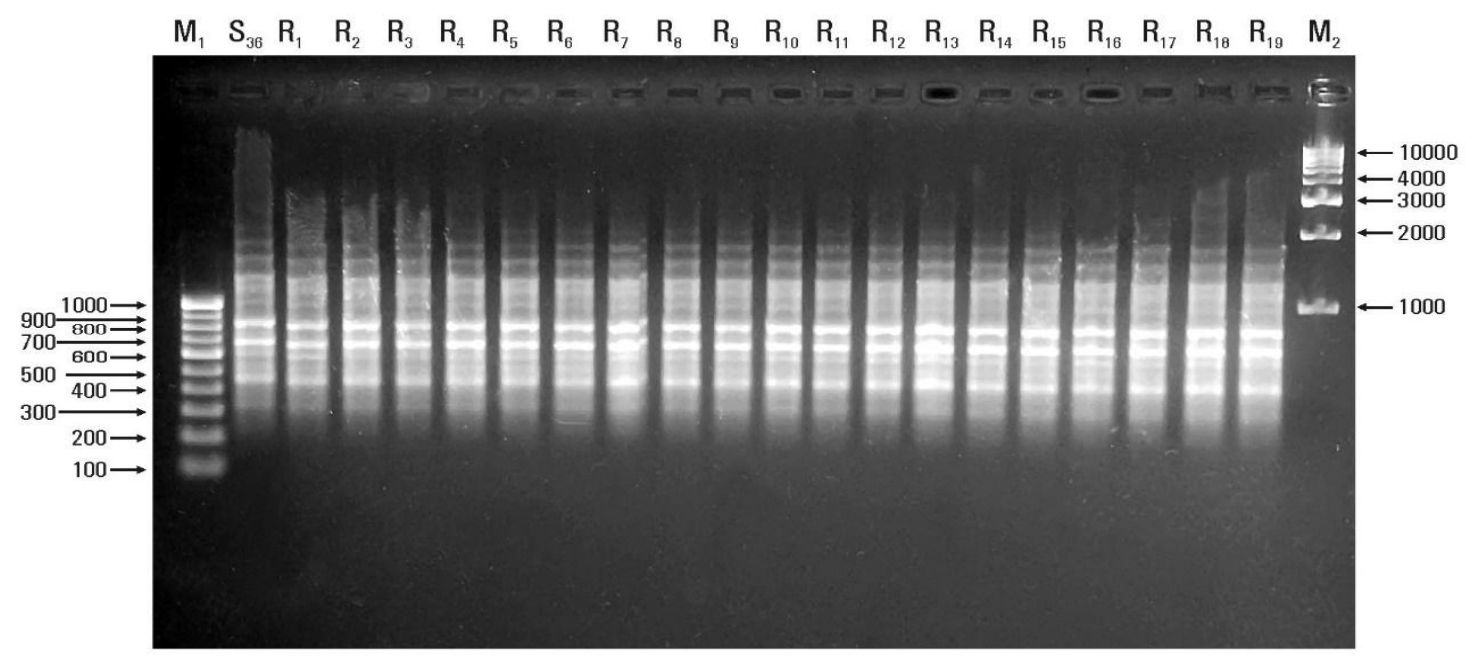


In conclusion, in this study, an efficient protocol for high frequency mass multiplication from nodal explants of $S$. rebaudiana through repeated subculture was reported. By using this protocol, minimum 2400 plants could be produced from a single microshoots within 12 weeks with 4 subculture. Therefore, multiplication of planting materials can be increased by many folds using more number of microshoots and producing true-to-type quality planting material. This protocol produce high amount of quality planting material within 12 weeks with higher survival rate. Hence, the protocol can be considered for high frequency mass multiplication of quality planting materials of stevia with high survival rate.

\section{Acknowledgement}

The study was supported by the Department of Science and Technology, Government of Rajasthan and Rajiv Gandhi National Fellowship by University Grant Commission, Government of India.

\section{References}

Ahmed, M.B., Salahin, M., Karim, R., Razvy, M.A., Hannan, M.M., Sultana, R., Hossain, M. and Islam, R.2007. An Efficient Method for in vitro Clonal Propagation of a Newly Introduced Sweetener Plant (Stevia rebaudiana Bertoni.) in Bangladesh. AmericanEurasian J. Scientific Res., 2: 121-125.

Alhady, M.R.A.A. 2011. Micropropagation of Stevia rebaudiana Bertoni. A New Sweetening Crop in Egypt. Global J. Biotechnol. Biochem., 6 (4): 178-182.

Awang, Y., Shaharom, A.S., Mohamad, R.B. and Selamat, A. 2009. Chemical and physical characteristics of cocopeatbased media mixtures and their effects on the growth and development of celosia cristata. American J. Agri. Biol.
Sci., 4: 63-71.

Carneiro, J.W.P., Muniz, A.S. and Guedes, T.A. 1997. Greenhouse bedding plant production of Stevia rebaudiana (Bert) Bertoni. Canadian J. Plant Sci., 77: 473-474.

Gantait, S., Das, A. and Mandal, N. 2015. Stevia: A Comprehensive Review on Ethnopharmacological Properties and In Vitro Regeneration. Sugar Tech., 17: 95-106.

Goettemoeller, J. and Ching, A. 1999. Seed Germination in Stevia rebaudiana. Perspect new Crop New Uses, 510-511.

Hassanen, S.A. and Khalil, R.M.A. 2013. Biotechnological studies for improving of stevia (Stevia rebaudiana Bertoni) in vitro plantlets. Middle-East J. Scientific Res., 14: 93-106.

Hazarika, B.N. 2006. Morpho-physiological disorders in in vitro culture of plants. Scientia Horticulturae, 108: 105-120.

Ibrahim, I.A., Nasr, M,I., Mohammed, B.R. and El-Zefzafi, M.M. 2008a. Plant growth regulators affecting in vitro cultivation of Stevia rebaudiana. SugarTech., 10: 254-259.

Ibrahim, I.A., Nasr, M.I., Mohammedm, B.R. and El-Zefzafi, M.M. 2008b. Nutrient factors affecting in vitro cultivation of Stevia rebaudiana. SugarTech, 10: 248253.

Jain, P., Kachhwaha, S. and Kothari, S.L. 2009. Improved micropropagation protocol and enhancement in biomass and chlorophyll content in Stevia rebaudiana (Bert.) Bertoni by using high copper levels in the culture medium. Scientia Horticulturae, 119: 315-319.

Kaeppler, S.M., Kaeppler, H.F. and Rhee, Y. 2000. Epigenetic aspects of somaclonal variation in plants. Plant Molecular Biol., 43:179-88.

Kalpana, M., Anbazhagan, M., Natarajan, V. and Dhanavel, D. 2010. Improved 
Micropropagation Method for the Enhancement of Biomass in Stevia rebaudiana Bertoni. Recent Res. Sci. Technol., 2: 8-13.

Laribi, B., Rouatbi, N., Kouki, K. and Bettaieb, T. 2012. In vitro propagation of Stevia rebaudiana (Bert.) -A non caloric sweetener and antidiabetic medicinal plant. Int. J. Medi. Aromatic Plants, 2: 2249-4340.

Lata, H., Chandra, S., Techen, N., Wang, Y.H. and Khan, I.A. 2013. Molecular Analysis of Genetic Fidelity in Micropropagated Plants of Stevia rebaudiana Bert. Using ISSR Marker. American J. Plant Sci., 4: 964-971.

Lee, M. and Phillips, R.L. 1988. The Chromosomal Basis of Somaclonal Variation. Annual Review of Plant Physiol. Plant Mol. Biol., 39: 413-437.

Modi, A.R., Patil, G., Kumar, N., Singh, A.S. and Subhash, N.2012. A Simple and Efficient In Vitro Mass Multiplication Procedure for Stevia rebaudiana Bertoni and Analysis of Genetic Fidelity of In Vitro Raised Plants Through RAPD. SugarTech., 14: 391397.

Jain, S. 2001. Tissue culture-derived variation in crop improvement. Euphytica, 118: 153-166.

Murasnige, T. and Skoog, F. 1962. A Revised Medium for Rapid Growth and Bio Agsays with Tohaoco Tissue Cultures. Physiologia Plantarum, 15: 473-497.

Murthy, B.N.S.,Murch, S.J. and Saxena, P.K. 1998. Thidiazuron: a potent regulator of in vitro plant morphogenesis. In Vitro Cellular \& Developmental Biol. Plant, 34: 267-275.

Phillips, R.L., Kaeppler, S.M. and Olhoft, P. 1994. Genetic instability of plant tissue cultures: breakdown of normal controls. Proceedings of the National Academy of Sciences, 91: 5222-6.

Pospisilova, J., Ticha, I., Kadlecek, P., Haisel,
D. and Plzáková, ̌ S. 1999. Acclimatization of micropropagated plants to ex vitro conditions. Biologia Plantarum, 42: 481-497.

Ramírez-Mosqueda, M.A. and IglesiasAndreu, L.G. 2016. Direct Organogenesis of Stevia rebaudiana Bertoni Using Thin Cell Layer (TCL) Method. SugarTech., 18: 424-428.

Rout, G.R., Samantaray, S. and Das, P. 2000. In vitro manipulation and propagation of medicinal plants. Biotechnol. Adv., 18: 91-120.

Shock, C.C. 1982. Rebaudi's stevia: natural noncaloric. Shock, 4-5.

Singh, P. and Dwivedi, P. 2013. Two-stage culture procedure using thidiazuron for efficient micropropagation of Stevia rebaudiana, an anti-diabetic medicinal herb. 3 Biotech., 4: 431-437.

Singh, P., Dwivedi, P. and Atri, N. 2014. In Vitro Shoot Multiplication of Stevia and Assessment of Stevioside Content and Genetic Fidelity of the Regenerants. SugarTech., 16: 430-439.

Sivaram, L. and Mukundan, U. 2003. In vitro culture studies on Stevia rebaudiana. In Vitro Cellular \& Developmental Biology-Plant, 39: 520-523.

Sreedhar, R. V., Venkatachalam, L., Thimmaraju, R., Bhagyalakshmi, N., Narayan, M.S. and Ravishankar, G.A.2008. Direct organogenesis from leaf explants of Stevia rebaudiana and cultivation in bioreactor. Biologia Plantarum, 52: 355-360.

Sung, J.H. 2006. Rapid in vitro propagation and enhanced stevioside accumulation in Stevia rebaudiana bert. J. Plant Biol., 49: 267-270.

Talukdar, M.C. and Bora, A. 2009. Effect of substrates, poly-tunnels and growing conditions on hardening of in vitro raised carnation plantlets. Indian $J$. Horticulture, 66: 225-228.

Tamura, Y., Nakamura, S., Fukui, H. and 
Tabata, M. 1984. Comparison of Stevia plants grown from seeds, cuttings and stem-tip cultures for growth and sweet diterpene glucosides. Plant Cell Reports, 3: 180-182.

Thiyagarajan, M. and Venkatachalam, P. 2012. Large scale in vitro propagation of Stevia rebaudiana (bert) for commercial application: Pharmaceutically important and antidiabetic medicinal herb. Industrial
Crops and Products, 37: 111-117.

Vasane, S.R. and Kothari, R.M.2008. An integrated approach to primary and secondary hardening of banana var. Grand Naine. Indian J. Biotechnol., 7: 240-245.

Yadav, A.K., Singh, S., Dhyani, D. and Ahuja, P.S. 2011. A review on the improvement of stevia [Stevia rebaudiana (Bertoni)]. Canadian J. Plant Sci., 91 (1): 1-27.

\section{How to cite this article:}

Manvendra Singh, Vinod Saharan, Deepak Rajpurohit, Yadunandan Sen, Arunabh Joshi and Ajay Sharma. 2017. Thidiazuron Induced Direct Shoot Organogenesis in Stevia rebaudiana and Assessment of Clonal Fidelity of Regenerated Plants by RAPD and ISSR. Int.J.Curr.Microbiol.App.Sci. 6 (8): 1690-1702. doi: https://doi.org/10.20546/ijcmas.2017.608.203 